\title{
Patient education interventions for optimizing bowel cleansing before colonoscopy: is the juice worth the squeeze?
}

Authors

Institution
Noor Mohammed, Ruchit Sood, Bjorn J. Rembacken

Leeds Gastroenterology Institute, St. James’s University Hospital, Leeds Teaching Hospitals NHS Trust, Leeds, United Kingdom submitted 21. October 2015 accepted after revision 3. November 2015

\section{Bibliography}

Dol http://dx.doi.org/ 10.1055/s-0041-109401 Endoscopy International Open 2015; 03: E653-E654 (c) Georg Thieme Verlag KG Stuttgart · New York E-ISSN 2196-9736

\section{Corresponding author}

Bjorn Rembacken, MD

Leeds Gastroenterology Institute

St. James's University Hospital Beckett Street

Leeds

LS9 7TF

United Kingdom

Fax: +44-113-206-8851

bjorn.rembacken@nhs.net
License terms

$(\circledast) \Theta \circledast$
Worldwide, colorectal cancer (CRC) is the third most common cancer and the fourth most common cause of cancer deaths [1]. Although treatments for CRC have advanced over the past decade, they have translated into only a modest benefit for patients who have advanced and metastatic CRC, and with significantly increased treatment costs [2]. The aim of national screening programs is to reduce the burden of CRC in the population. Screening for CRC with colonoscopy has been shown to be cost-effective in detecting and removing adenomas, which are the clinical precursors of CRC, and several large studies have demonstrated that high quality colonoscopy can improve outcomes with a substantial reduction in CRC rates [3,4]. However, the detection of precursor lesions and early CRC depends on a number of factors, including adequate bowel preparation, and studies have shown that inadequate bowel cleansing increases the risk that flat adenomas and other high risk lesions will remain undetected $[5,6]$.

The reasons for not adhering to bowel-cleansing instructions before colonoscopy are likely to be multifactorial; both patient-related factors (e.g., limited mobility, language barriers, illiteracy) and factors related to the bowel-cleansing agent itself (e.g., unpalatability, the large volume that must be consumed, side effects such as nausea and headache) are worth considering. Patient educational interventions are thought to result in an improved quality of bowel preparation, and in practice they should result in increased rates of adenoma detection.

In this month's issue, a meta-analysis by Chang et al. summarizes the outcomes of patients who receive educational intervention compared with the outcomes of those who receive no intervention in regard to the quality of bowel preparation and the polyp detection rate. Nine randomized controlled trials (RCTs) enrolling 2885 patients were included in the meta-analysis. The educa- tional interventions used were pamphlets, booklets, videos, questionnaires, and visual aids in seven studies, and mobile phone messages and telephone consultations in the remaining two studies. The authors reported an overall significant improvement in the quality of bowel preparation in patients who received educational intervention compared with those who did not, irrespective of whether the intervention was conducted directly by health professionals $(\mathrm{RR}=1.19 ; 95 \% \mathrm{Cl}$ $1.08-1.32$ ) or consisted of self-directed learning with provided materials $(\mathrm{RR}=1.22$; $95 \% \mathrm{Cl} 1.05-$ 1.42). Perhaps disappointingly, the improvement in the quality of bowel preparation did not translate into a significant improvement in the polyp detection rate, although only three of the nine studies reported this particular outcome, and as the authors state, the data were insufficient to allow any meaningful conclusions for this outcome to be drawn. Furthermore, the polyp detection rate is likely to depend on other factors not assessed in these studies, such as withdrawal time and colonoscopist experience. A limitation of this meta-analysis was that the scales used to assess the quality of bowel preparation, the types of bowel purgative, and the timing of administration (single vs. split dose) differed among the included studies, resulting in significant heterogeneity.

Educational intervention to ensure adequate bowel cleansing before colonoscopy is likely to be most beneficial in a small but significant subset of "high risk" patients, and identifying these patients and tailoring the intervention to their individual needs remains the challenge. One size does not fit all! The use of electronic media, such as smartphone applications and interactive online educational material, is attractive. However, simple interventions, such as face-to-face consultations to overcome language and educational barriers in high risk patients, may be just as important. 


\section{Competing interests: None}

\section{References}

1 Ferlay J, Soerjomataram I, Ervik M et al. Globocan 2012. Estimated cancer incidence, mortality and prevalence worldwide in 2012. Available from: http://globocan.iarc.fr/Default.aspx (Accessed 5 November 2015)

2 Schreuders EH, Ruco A, Rabeneck $L$ et al. Colorectal cancer screening: a global overview of existing programmes. Gut 2015; 64: 1637-1649

3 Zauber AG, Winawer SJ, O'Brien MJ et al. Colonoscopic polypectomy and long-term prevention of colorectal-cancer deaths. N Engl J Med 2012; 366: $687-696$
4 Kaminski MF, Regula J, Kraszewska E et al. Quality indicators for colonoscopy and the risk of interval cancer. N Engl J Med 2010; 362: $1795-1803$

5 Xiang $L$, Zhan $Q$, Zhao XH et al. Risk factors associated with missed colorectal flat adenoma: a multicenter retrospective tandem colonoscopy study. World J Gastroenterol 2014; 20: 10927-10937

6 Singhal S, Virk MA, Momeni M et al. Impact of bowel preparation on surveillance colonoscopy interval. Scand J Gastroenterol 2014; 49: 885-890 